\title{
AS REVISTAS ACADÊMICAS EM CIÊNCIAS SOCIAIS Antinomias entre conhecimento e norma (métricas)
}

\author{
Anete B. L. Ivo \\ Universidade Federal da Bahia \\ Programa de Pós-Graduação em Ciências Sociais | Salvador, Brasil \\ Editora do Caderno CRH (1995-2013) \\ anetivo@hotmail.com | ORCID iD: 0000-0002-9004-3607
}

$\mathrm{C}$ onsideradas como espaço de troca, lugar de debate e difusão de conhecimentos, de onde emergem análises inovadoras na apresentação de teorias e experiências de pesquisa, as revistas científicas se constituem num componente relevante da vida acadêmica e da comunidade científica ${ }^{1}$. Elas têm sido avaliadas segundo critérios paramétricos que incidem simbolicamente sobre avaliações meritocráticas na seleção de projetos, no desempenho de programas de pós-graduação e no reconhecimento dos pesquisadores de cada área.

Este artigo busca conceituar as revistas como bem público e coletivo ${ }^{2}$ que integra o campo de produção e reprodução do saber, participando do desenvolvimento e da legitimidade de uma disciplina ou área (Boure 1993; Renucci e González, 2017), no caso, a das ciências sociais. A tarefa implica o esforço de situar uma revista em sua relação com a reprodução do campo científico, desenvolvendo, em caráter preliminar, um esboço de algumas contribuições da teoria sociológica que nos auxiliam a entender o campo científico. Discute também a

\footnotetext{
${ }^{1}$ A importância das revistas não exclui o reconhecimento da publicação em livros como veículo importante de produção na área das ciências humanas e sociais.

2 Ver Ivo (2015) Seção Especial (SE) - "As políticas para a publicação científica: perspectivas para os periódicos de ciências sociais". $39^{\circ}$ Encontro Anual da Anpocs, 26-20 de outubro de 2015, Caxambu-MG. Disponível em: https://www.youtube.com/watch?v=UDfszNKZ9Ho
} 
prevalência racional-instrumental do uso de métricas na avaliação de desempenho das pós-graduações e das revistas no campo das ciências sociais. O ponto sensível da crítica desenvolvida neste artigo é o de que a validação das ciências humanas e sociais, quando normatizada segundo indicadores da cienciometria ${ }^{3}$ (fatores de impacto e critérios de internacionalização etc.), baseados, sobretudo, em critérios apropriados às ciências da natureza contrapõe-se aos princípios epistemológicos das humanidades, de caráter sócio-histórico e interpretativo.

\section{As revistas acadêmicas como esfera pública nas ciências sociais}

A produção do conhecimento é um bem público e coletivo, que se situa no tempo e só se completa plenamente pela externalização dos resultados na esfera pública - acadêmica e social. Como afirma Boure (1993:99), a revista é parte "[...] do funcionamento geral das ciências, de suas instituições, de seus pesquisadores, mas, também, da relação que cada disciplina mantém consigo mesma, com as outras disciplinas e com a sociedade”. Esse pressuposto expõe a complexidade implícita à sua produção e gestão e orienta a relação intrínseca e necessária entre a produção do conhecimento, a comunicação científica e a publicação de seus resultados, em todas as suas manifestações, estágios de desenvolvimento e suportes acadêmicos ${ }^{4}$.

A produção do conhecimento, portanto, está necessariamente associada à publicização de seus resultados e à crítica pelos pares. Essa relação entre conhecimento, comunicação científica e esfera pública (dentro e fora da academia) tem implicações epistemológicas e institucionais sobre o processo de preparação de uma revista científica, e envolve uma ética do trabalho que preside a natureza das decisões e a definição de competências entre os diferentes atores que integram o processo de produção editorial: autores, revisores, financiadores, equipe técnica de gestão, editores e corpo editorial. Ademais, essa ética embasa as relações da revista com

\footnotetext{
${ }^{3}$ A cienciometria "trata da análise de aspectos quantitativos referentes à geração, propagação e utilização de informações científicas, com o fim de contribuir para o melhor entendimento do mecanismo de pesquisa científica como uma atividade social" (Pinto e Andrade 1999:448 apud Meis e Leta 1996).

${ }^{4}$ Desde a elaboração de monografias e teses, passando pelas comunicações em congressos e pela publicação em livros e revistas.
} 
as agências de fomento, os indexadores científicos e a instituição. A compatibilização dessas diversas dimensões é realizada pelos editores, responsáveis por garantir a qualidade dos textos, cumprir a missão institucional e promover a mediação entre os autores e o público receptor.

Como definem Renucci e González (2017: 4), as revistas ajudam a legitimar o conhecimento ao promoverem o "[...] aggiornamento dos dados, a reação rápida aos debates e controvérsias, a transcrição desses debates, a multiplicação da oferta de leituras num mesmo domínio, a plasticidade, a circulação das informações etc." Portanto, uma revista acadêmica constitui-se num produto singular, que envolve a preparação e a qualificação acadêmica dos textos e sua seleção para o debate público, participando, portanto, do fazer e da reprodução do fazer científico, nas distintas áreas do conhecimento ${ }^{5}$.

Do ponto de vista do formato, as revistas científicas são publicações acadêmicas seriadas e periódicas, padronizadas quanto às regras científicas e às normas preestabelecidas para sua edição, veiculando resultados de pesquisas para o público de uma ou mais áreas do conhecimento, ou de uma determinada linha de investigação. Constitui-se num dos principais veículos de comunicação científica, pois estimula o debate entre especialistas e supõe processos preparatórios de revisão, visando à qualificação do artigo e à garantia de integridade do periódico.

Portanto, uma revista combina duas dimensões: uma formal, que atende às regras da escrita científica e aos critérios de padronização do periódico, e outra relacionada ao conteúdo, de natureza epistemológica e cognitiva, segundo Boure (1993). Do ponto de vista formal, sua edição obedece às regras do método científico (abordagem crítica e metodológica, uso de vocabulário e conceitos especializados, inclusão de notas e referenciais bibliográficos pertinentes, indicação de evidências etc.). Quanto ao conteúdo, articula três dimensões: explicita a ambição cognitiva ou interpretativa do problema, referindo-se a uma abordagem teórica e (ou) metodológica validada; esclarece o caminho lógico

\footnotetext{
${ }^{5}$ Esses atributos científicos se distinguem da produção em livro pela forma de organização do conteúdo, pela densidade dos resultados e pelo tempo para sua elaboração, o que, no caso de livros, exige maior tempo na escrita e análises mais abrangentes. Mas são convergentes quanto ao rigor científico, metodológico e da estrita culta.
} 
da investigação e a lógica da exposição; e localiza o artigo num campo científico de uma ou mais áreas do conhecimento.

O processo de revisão pelos pares e a preparação dos textos permitem que os artigos publicados em periódicos científicos ganhem legitimação e reconhecimento acadêmico, tanto para os autores como para as instituições em que eles estão inseridos. Dessa forma, a revisão editorial representa uma forma indireta de controle e validação dos resultados pela comunidade científica e legitima esse conhecimento pelo aperfeiçoamento crítico continuado da comunidade.

O fato de os autores e o público leitor desses periódicos serem partes de uma mesma comunidade de ciência também singulariza a revista científica. Ademais, no domínio das humanidades, as revistas seguem algumas características artigos mais longos, argumentos discutidos, rigor conceitual e estilo de redação - que favorecem um debate de fundo da pesquisa. Desse modo, os textos de uma revista científica, nesse domínio, distinguem-se dos artigos de comunicação na mídia, que cumprem a função de informar o público e formar opinião. Embora de grande relevância na arena pública, eles são distintos quanto à natureza, seja pelo público receptor - no caso das revistas cientificas, mais restrito -, seja quanto ao conteúdo, que, nas revistas acadêmicas, segue exigências epistemológicas distintas, ainda que o jornalismo científico se aproxime desses mesmos requisitos.

Portanto, um artigo submetido à revista, ao passar pelas diferentes instâncias de avaliação e revisão, resulta num produto acadêmico renovado e, na maioria das vezes, alcança ganhos qualitativos (consistência dos argumentos, retificações conceituais, maior clareza, entre outros aspectos). A edição de uma revista articula, portanto, atividades-fim, de produção do conhecimento, atividades-meio, na gestão do fluxo, distribuição, financiamento e estoques, e atividades de produção editorialgráfica, que dão forma ao produto final. Forma e conteúdo estão intrinsecamente relacionados, de maneira que a gestão de um periódico deve estar sintonizada com a dinâmica da vida acadêmica e que o projeto gráfico-editorial ilumine a mensagem dos autores e expresse a identidade institucional.

A produção do conhecimento, como atividade social, é cumulativa no tempo, dialoga com a produção acadêmica préexistente, projetando-se como um novo insumo para o avanço do conhecimento e para o reconhecimento das inovações 
produzidas, atualizando-os. Exige que o pesquisador dialogue com a literatura do seu campo de conhecimento, o que possibilita situar sua contribuição no estágio de desenvolvimento dos estudos de um determinado tema. Essa dialética autorreflexiva, crítica e situada preside a produção acadêmica e é intrínseca à ética do trabalho acadêmico ${ }^{6}$.

\section{Esboço preliminar de uma "sociologia das ciências"}

O campo das ciências se estrutura segundo grandes áreas de conhecimento que expressam singularidades epistemológicas de seu objeto e método e das formas de comunicação e seus usos sociais. A lógica que preside a divisão das ciências reconhece, portanto, a natureza epistemológica distinta de cada campo de saber, e elas têm uma relação direta com a escolha de suportes para a publicação de seus resultados, os circuitos das ideias e os destinos sociais finais desses resultados. Esses usos sociais é que se constituem nos verdadeiros impactos sociais, em termos de apropriação real de saberes pela sociedade.

As ciências da natureza, por exemplo, devido a seu caráter experimental e a suas práticas de laboratório, veiculamos resultados de suas pesquisas, sobretudo, em artigos de periódicos que se constituem em canais mais imediatos de intercâmbio, favorecendo avanços nos experimentos, o que é distinto das pesquisas em humanidades, cujo caráter interpretativo e discursivo influencia a elaboração de textos mais longos e envolve também a publicação em livros. Elas estudam a sociedade, o ser humano, os fenômenos sociais, e têm um componente fortemente histórico e cultural. Assim, os pesquisadores das ciências naturais priorizam a publicação dos resultados em periódicos científicos e em inglês básico, enquanto, os pesquisadores, na área das humanidades, além das revistas, publicam frequentemente em livros, pela extensão dos argumentos e a mobilização do debate ${ }^{8}$. Esse habitus acadêmico

\footnotetext{
6 O diálogo com a literatura, portanto, não é apenas uma etapa formal, mas se constitui num exercício autorreflexivo, que situa a contribuição no estágio pré-existente do conhecimento e integra uma ética de pesquisa.

7 O tema é ambicioso, mas, neste texto, tem função apenas indicativa, sugerindo pistas teóricas para os que se propõem a uma análise mais aprofundada do campo científico.

8 Em 1982, os livros correspondiam a 20\% das publicações de pesquisadores no domínio das ciências humanas e sociais, e apenas a 1,3\% das publicações em ciências exatas e naturais. 54\% das pesquisas em
} 
diferencial faz com que os pesquisadores das ciências naturais e exatas tenham maior incidência de publicações em periódicos estrangeiros e em inglês, o que influencia alcançarem comparativamente maiores rankings internacionais de impacto.

\section{Algumas contribuições teóricas para a análise do campo científico}

A institucionalização do campo científico tem sido objeto de algumas contribuições da teoria sociológica ${ }^{9}$. Robert Merton desenvolveu uma sociologia da ciência a partir de uma perspectiva funcionalista, definindo princípios que são parte do ethos científico ${ }^{10}$. Karl Mannheim considera a contextualização sócio-histórica da epistemologia das ciências na vida pública. $\mathrm{E}$ Pierre Bourdieu traz contribuições relevantes sobre a estruturação do "campo científico" e do "habitus acadêmico".

Merton (1974) esclareceu princípios e regras de conduta científica, sem desconhecer a influência dos valores culturais na produção das ciências. Para ele, a institucionalização do campo científico observa quatro princípios: universalismo; "comunismo", no sentido de servir à sociedade e ao bem comum; desinteresse (em termos de interesses pessoais) pelo compromisso do pesquisador com o progresso da ciência; e um ceticismo organizado, que submete os resultados da ciência à crítica continuada da comunidade científica. Esses princípios se constituem em critérios de validação científica adotados nas instituições científicas americanas e são legitimados pelas comunidades científicas de todo o mundo, afirmando-se como universais, embora reconheçam as especificidades dos diversos campos de conhecimento.

Karl Mannheim destaca as circunstâncias sóciohistóricas que acolhem a possibilidade do conhecimento objetivo socialmente enraizado. Esse enquadramento sócio-histórico da reflexão epistemológica, para Karl Mannheim, considera os pesquisadores como parte de uma intelligentsia que busca

ciências exatas e naturais foram publicadas no estrangeiro e $75 \%$ das pesquisas em ciências humanas em revistas nacionais (Cf. Castro1978).

9 Ver Bertelli, Antônio R. et al. (1967), que reúne artigos de Karl Mannheim, Robert K. Merton e C. Wright Mills.

10 Ou seja, um conjunto dos costumes e hábitos de comportamento (instituições, afazeres etc.) e da cultura (valores, ideias ou crenças), característico da coletividade científica. 
compreender como as ciências sociais interagem diretamente com a democracia, seus atores e seus processos ${ }^{11}$.

Considerando o campo científico uma atividade social e histórica, Pierre Bourdieu (2000) argumenta que a produção do conhecimento é condicionada por um contexto sociocultural e permeada por valores e lutas internas por competências. Ele recusa a divisão clássica entre dois tipos de ciências: as naturais, explicativas, que relacionam causas e efeitos, e as compreensivas, que se utilizam da intuição, da interpretação etc. Para ele, a teoria social, que serve para explicar as práticas dos outros, também serve para explicar a própria construção da ciência social. Ela expressa um campo político de luta entre pesquisadores pelo controle de recursos e busca por reconhecimento. Dessa perspectiva, a linguagem e os conceitos sociológicos constituem parte dos processos sociais reais, uma vez que as representações sociais e os significados que os atores têm sobre os fenômenos sociais são também constitutivos da ordem social e da construção da ciência ${ }^{12}$.

A sociologia da ciência ${ }^{13}$ de Merton seria orientada pela ação individual do cientista, julgado e avaliado pelas expectativas e valores de sua sociedade. Mannheim e Bourdieu reconhecem a historicidade como componente da explicação dos fenômenos sociais e culturais e situam esse conhecimento no campo de lutas por hegemonia, distinguindo-se de uma concepção pragmática da ciência positiva, orientada segundo a escolha racional ${ }^{14}$.

\section{Globalização, circulação das ideias e imperativos da internacionalização}

O contexto da globalização e a integração dos países em cadeias globais - seja quanto à disseminação de processos sociais, seja na propagação de riscos - têm imposto novos desafios à produção científica, visando a promover a circulação das ideias em dinâmicas transnacionais, o que se traduz em políticas de intercâmbio científico internacional, especialmente a partir da década de 1990. A internacionalização do conhecimento passa

\footnotetext{
11 Ver o capítulo “O problema da 'intelligentsia': um estudo do seu papel no passado e no presente", em Mannheim (1974).

12 Do autor: Homo Academicus. Paris: Ed. Minuit, 1984; Les usages sociaux de la science: pour une sociologie du champ scientifique, Paris: INRA, 1997.

13 Ver Robert K. Merton. The Sociology of Knowledge, 2013[1937].

14 Essa abordagem da ciência positiva se define em oposição às teorias normativas.
} 
a ser considerada, então, "o estágio mais elevado das relações internacionais entre as universidades" (CAPES 2017a:6).

Há de se considerar, contudo, os critérios dessa internacionalização no domínio das ciências humanas e sociais. Como elas não dispõem de uma teoria integrada para explicar a diversidade dos fenômenos sociais, parece pertinente ter consciência da contextualidade, que expõe singularidades e especificidades geopolíticas e sócio-históricas, considerando os elementos do ambiente que influenciam cada sociedade. Portanto, importa também reconhecera contribuição do conhecimento que as sociedades do Sul têm produzido sobre elas mesmas, cujos pressupostos são distintos daqueles que comandam a produção científica dos países do Norte, e que possibilita construir uma ciência atenta à diversidade das experiências históricas e culturais num mundo globalizado. Essa contextualização redefine a relação entre o local e o global, e condiciona a validade de seus argumentos às consequências de seu envolvimento no mundo. Nesse sentido, redefine-se a relação entre internacionalização e produção local ou regional, uma vez que a globalização do conhecimento se afirma, muitas vezes, pelo seu localismo ou regionalismo.

\section{A produção em ciências sociais: a armadilha das métricas}

O campo científico tem sido acompanhado por um crescente processo de avaliação do desempenho e aferição da produtividade, de natureza paramétrica, que alcança também a classificação das revistas. Essa tendência resulta, de um lado, da expansão das comunidades científicas, e, de outro, da influência da cienciometria na construção de indicadores, entre eles ode impacto.

As diversas comissões de Área da Sociologia ${ }^{15}$ ao longo dos últimos anos na CAPES, reconhecendo as especificidades da produção nacional, têm buscado aferir a produção da área de forma mais afinada à realidade da produção nacional, incorporando tanto a publicação científica em revistas como em livros. Nas normas de classificação dos periódicos do sistema Qualis $^{16}$ de revistas, tomaram por base a indexação dos títulos em

\footnotetext{
${ }^{15} \mathrm{E}$ demais áreas das ciências sociais e sociais aplicadas.

16 O Qualis da CAPES afere a qualidade dos artigos a partir dos veículos de publicação para atender às necessidades do sistema de avaliação das
} 
importantes bancos de dados e indexadores de referência e qualificação bibliográfica. Assim, o fator de impacto foi considerado, mas não condicionou a avaliação (CAPES 2017b).

Essa posição, no entanto, tem sido questionada no debate geral entre as áreas, sob a alegação de que os indicadores quantitativos (fator de impacto) seriam mais universais e menos sujeitos a vieses subjetivos. Assim, todas as área foram pressionadas ${ }^{17}$ a adotar, para a internacionalização, o fator de impacto $(\mathrm{h} 5)^{18}$ das revistas, o que coloca os periódicos do domínio das humanidades em posição desfavorável tanto no sistema Qualis de revistas como no sistema de C\&T nacional. Ou seja, como a Área das Humanidades é sub-representada nas bases do Institute for Scientific Information - ISI, já que boa parte da sua produção é publicada em livros, o fator de impacto do ISI não reflete a produção da área. Tendo em vista que as agências de fomento nacionais consideram esses rankings na distribuição de investimentos em C\&T, o uso desse critério acaba sendo cumulativamente prejudicial e discriminatório em relação a uma importante área do saber.

Uma métrica é um constructo matemático dissociado das condições particulares de realização das práticas científicas e da ordem social na qual essas práticas humanas se constituem. Não existe neutralidade em sua construção, já que ela é condicionada por uma cultura e uma tradição em ciências e definida por metodologias construídas por pesquisadores e orientados segundo objetivos, critérios e percepções específicas.

A universalidade do uso de um indicador para validar o que é distinto, por natureza, consolida um processo de hegemonia das ciências exatas e da natureza no sistema de C\&T ${ }^{19}$ que, sob a alegação de uniformidade de critérios objetivos de internacionalização, interfere na autonomia da área

\footnotetext{
Áreas, ou seja, periódicos científicos e anais de eventos, com base no levantamento da produção dos programas de pós-graduação brasileiros. $17 \mathrm{O}$ que não ficou decidido, encontrando-se, ainda, em discussão.

18 O Fator de Impacto (FI) é a principal métrica utilizada para avaliar as revistas científicas por todo o mundo, ao contabilizar as citações recebidas. É indexado pelo Institute for Scientific Information/Thompson Scientific Reuters (ISI) e publicado pelo fournal of Citation Report (JCR).

${ }^{19} \mathrm{O}$ uso do fator de impacto é polêmico, inclusive em outras disciplinas, como a Química. Entre outros argumentos porque, muitas vezes, os artigos mais citados são exatamente aqueles que apresentam erros interpretativos. Ademais, o imperativo de publicar pode sacrificar a formação crítica e consistente da produção à custa da obtenção de índices numéricos (cf. Pinto e Andrade 1999:452).
} 
das ciências sociais ${ }^{20}$. Como analisam Santos e Jeolas (2015), discutindo a submissão das pesquisas à avaliação do Comitê Nacional de Ética em Pesquisa- CONEP (Ministério da Saúde), ao se desconsiderar "os diferentes métodos das pesquisas sociais e a diversidade de perspectivas de análise, [anula-se] [...] o seu 'potencial crítico' e sua mais genuína contribuição para a sociedade" (11). Para esses autores, as “[ [..] contradições entre a ética - resultante da história dos homens e as normas [...] instituídas pela força, ou pelo poder dos homens, [...]podem vir a retirar da ética as dimensões da liberdade e do livre-exame, em vez de preservá-las [...]" (ibidem).

Essa ambivalência do poder da norma sobre a autonomia da pesquisa, no domínio das humanidades, expressa um conflito cognitivo no processo de conhecimento. As ciências sociais não lidam com experiências em seres humanos, mas com a interpretação e os significados da organização das comunidades e sociedades. Oferecem a palavra, os diagnósticos e o debate na compreensão da organização das sociedades, auxiliando na interpretação e na formulação crítica das políticas e da vida coletiva.

\section{Conclusão}

Os elementos analíticos expostos neste artigo indicam tensões entre os princípios que presidem a construção do conhecimento e o poder das normas que se instituem como um sistema de vigilância externa, indissociavelmente cognitivo e político. A prevalência de uma racionalidade cognitivoinstrumental (expressa nas métricas) (des)legitima grande parte do conhecimento produzido pelas ciências humanas e sociais nacionais.

$\mathrm{O}$ enquadramento das formas de produzir restrito ao fator de impacto alimenta um círculo vicioso no qual os estímulos à produção se constituem, ao mesmo tempo, em insumos que sacrificam a formação crítica da própria ciência, comprometem a qualidade científica (pela impulsão em publicar a qualquer

${ }^{20}$ Esse argumento expõe apenas as possíveis distorções no uso desses parâmetros. Eles podem também estimular uma competição entre áreas. Aqui não se trata disso, mas apenas de garantir às Humanidades a capacidade de responderem aos imperativos de produção, internacionalização e impacto de acordo com suas propriedades epistemológicas. 
custo) e superpõem a prevalência da técnica sobre o conhecimento.

Os parâmetros adotados, ao desconhecerem as condições específicas da produção do conhecimento em ciências humanas e sociais, colocam programas e pesquisadores em posições desfavoráveis na distribuição dos recursos, além de reforçar, simbolicamente, a deslegitimação dessas ciências. A "normose acadêmica", expressa pela obsessão por publicar a todo o custo, produz, no seu reverso, e "como sua maior vítima, o próprio conhecimento, quando privilegia as métricas e não os conhecimentos inovadores", como argumenta apropriadamente Souza (2014).

\section{Referências bibliográficas}

BERTELLI, Antônio R.; PALMEIRA, Moacir; VELHOR, Otávio Guilherme. 1967. Sociologia do Conhecimento. Rio de Janeiro: Zahar Editora.

BOURDIEU, Pierre. 1984. Homo Academicus. Paris: Ed. Minuit.

1997. Les usages sociaux de la science: pour une sociologie du champ scientifique, Paris: INRA.

2000. Esquisse d'une theórie de la pratique. Paris: Éditions du Seuil.

BOURE, Robert. 1993. "Sociologie des revues de sciences humaines et sociales". Réseaux 58:91-105.

CAPES. 2017a. A internacionalização na Universidade Brasileira: resultados do questionário aplicado pela CAPES. Brasília: CAPES.

2017b. Relatório de Avaliação Quadrimestral de Sociologia. Brasília: CAPES.

PINTO, Angelo C.; ANDRADE, Jailson. 1999. "Fator de impacto de revistas científicas: qual o significado deste parâmetro?". Química Nova 22(3): 448-453.

MANNHEIM, Karl. 1974. Sociologia da Cultura. São Paulo: Editora Perspectiva.

MERTON, Robert. 2013. Ensaios de sociologia da ciência. São Paulo: Editora 34.

1974. "Os imperativos institucionais da ciência". In: $A$ crítica da ciência. Rio de Janeiro: Zahar. p. 37-52. 
12 | ANETE IVO

RENUCGI, Florence e GONZÁLEZ, Irene González. 2017. "L'empire des revues". Clio@ @Themis, Revue électronique d'histoire du droit 12:1-7.

SANTOS, Luiz Antonio de Castro; JEOLÁS, Leila. 2015. "A pesquisa e sua ética, o poder e sua norma". Revista Brasileira de Sociologia 3(5):11-30.

SOUZA, Renato Santos de. 2014. "A doença da 'normalidade' na Universidade". In: NASGIMENTO, L. F. M. (org.). Lia, mas não escrevia (livro eletrônico): contos, crônicas e poesias. Porto Alegre: LFM.

Enviado: 1 de dezembro de 2020

Aceito: 7 de dezembro de 2020 